\title{
B CHROMOSOMES IN RATTUS FUSCIPES I. MITOTIC AND MEIOTIC CHROMOSOMES AND THE EFFECTS OF $B$ CHROMOSOMES ON CHIASMA FREQUENCY
}

\author{
R. L. THOMSON,* M. WESTERMAN $\dagger$ AND N. D. MURRAY† \\ * Dept. of Microbiology and + Dept. of Genetics and Human Variation, LaTrobe University, \\ Bundoora, Victoria, 3083, Australia.
}

Received 11.x.83

\section{SUMMARY}

The small heterochromatic $B$ chromosomes of Rattus fuscipes assimilis are similar to those described by others in the related species Rattus rattus. They are apparently stable in somatic tissues, but in male meiosis they are liable to non-disjunction. The $B$ chromosomes in $R$. $f$. assimilis are associated with an increase in the mean cell chiasma frequency, at least in males.

\section{INTRODUCTION}

A large number of plant and animal species have some individuals which carry apparently non-essential chromosomes in addition to their normal complement. These chromosomes have been described variously as "supernumerary," "accessory" or " $B$ " chromosomes (see Battaglia 1964, Muntzing 1974, Jones 1975, and Volobujev 1981 for reviews).

$B$ chromosomes $(B s)$ are frequently characterised by unconventional disjunction in germ line cells, although the precise pattern of behaviour varies between species (Jones, 1975). This is not only true of the oft-studied grain-bearing plants and orthopteran insects, but also of the relatively poorly known mammalian species with $B s$. There are six mammalian species in which detailed studies have been reported of germ line disjunction or transmission of $B s$ to offspring. These are: the harvest mouse, Reithrodontomys megalotis (Shellhammer, 1969), the pocket mouse, Perognathus baileyi (Patton, 1977), the black rat, Rattus rattus (Pretel and Diaz de la Guardia, 1978; Yosida, 1977), the red and silver foxes, Vulpes vulpes and $V$. fulvus (Volobujev, 1981), and the hooved lemming, Dicrostonyx torquatus (Gileva and Chebotar, 1979). In each of these species there is some evidence of a non-Mendelian accumulation mechanism which allows the production of more $B$ chromosome-bearing gametes than expected. The consequences of such an accumulation at the population level are unknown and because of this, the present project was initiated. The aim was to tie-in a study of the cytogenetics of a $B$ chromosome system with observations on the transmission rates of $B s$ from parents to offspring and to use this data in conjunction with information from a study of the population genetics of $B$ chromosomes.

The Australian bushrat, Rattus fuscipes is a species ideally suited to such a study. Baverstock et al., (1977) have described the $B$ chromosomes of $R$. $f$. assimilis, a subspecies which is native to southeastern Australia. It is one of the most common small mammals in this region, and its biology 
is fairly well known. It has the added advantage of being reasonably easily bred in the laboratory, which allows directed crosses to be made for transmission studies.

The present paper describes the structure of the $B$ chromosomes in Rattus fuscipes assimilis and their behaviour at mitosis and meiosis. It forms the background for a population study (Thomson, 1984) which gives an assessment of the fitness of $B$ chromosome-bearing individuals in natural populations.

\section{MATERIALS AND METHODS}

(i) Culture methods for karyotypes

(a) Short term leukocyte culture

Two techniques were used, either that of Baverstock et al., (1977) or that of de Boer et al., (1977). The latter technique is notable for the use of Concanavalin A as a mitogen, and the higher dose of Glutamine.

\section{(b) Long term tissue culture}

Initiation of monolayer cultures from various tissues was achieved by the method of Jovanavic and Atkins (1969), modified by the use of foetal calf serum in place of chicken plasma and serum for adhering tissue fragments to the bottom of culture bottles.

\section{(c) Short term tissue culture}

Liver from newborn rats and spleen from adult rats could be cultured to make chromosome preparations within two hours of sacrificing the animal with modification of the methods of Evans et al., (1972) and Stock et al., (1972).

Bone marrow chromosome preparations were made using the methods of Yosida and Sagai (1973), and corneal epithelium by the method of Fredga (1964).

\section{(ii) Chromosome banding techniques}

$G$ and $C$ bands were obtained by the methods of Yosida and Sagai (1973). For Nucleolus Organiser Region (NOR) bands, the method of Munke and Schmiady (1979) was used.

\section{(iii) Meiotic chromosomes}

Chromosome spreads were obtained from testes using a technique similar to that of Stock et al., (1972), the critical steps being the dissolution of the seminiferous tubules with 60 per cent acetic acid and the careful spreading of cells onto hot $\left(60^{\circ}\right)$ slides by using a $1 \mathrm{ml}$ syringe and $23 \mathrm{~g}$ needle. The suspension is expelled onto the slide, then the droplet drawn back into the syringe, leaving a circular film. This process is repeated several times on the one slide, the slides are allowed to dry, and are then stained with Giemsa or aceto-orcein. 
a
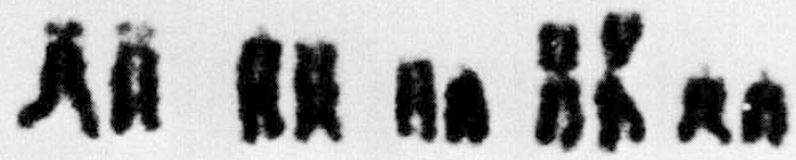

1

2

3

4

5

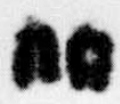

กด คด ห้ด้คด

6

7

8

9

10

11

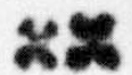

12

논 ํㅜㄴ

17

\section{3}

18

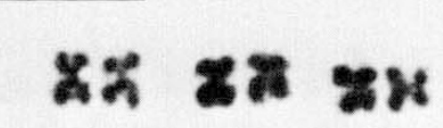

14

16

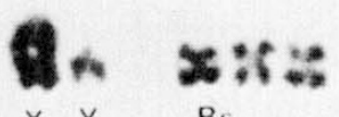

$X Y \quad B s$

b

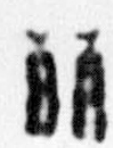

1

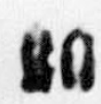

6

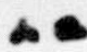

11

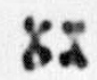

12

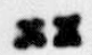

17

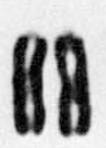

2

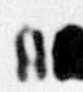

7

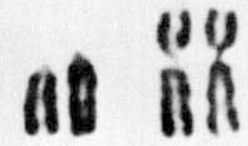

4

46 an

5

no

9

10
8

ไรั

14 in

16

PLATE 1. The unbanded mitotic metaphase chromosomes of Rattus fuscipes assimilis. 1(a) Male. 1(b) Female. $B$ chromosomes are indicated. 
a

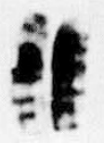

1

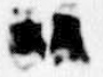

6
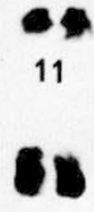

11

12

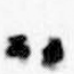

17

17

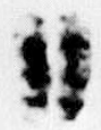

2

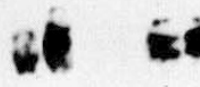

8

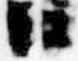

9

10

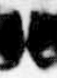

5

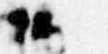

7

4

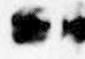

13

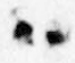

15

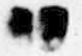

17

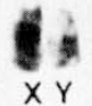

B

b

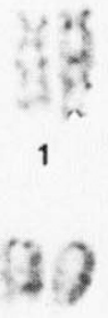

6

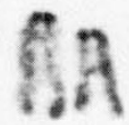

2

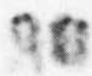

7

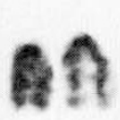

3

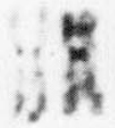

4

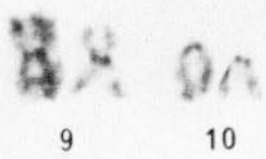

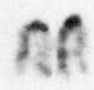

10

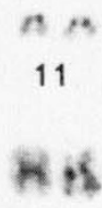

12

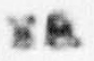

17

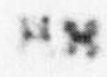

13

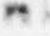

18

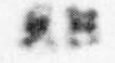

14

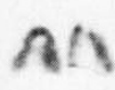

8 


\section{RESUlTS AND DISCUSSION}

\section{(i) The somatic chromosomes}

The standard karyotype of Rattus fuscipes assimilis has been described by Yosida et $a l$., (1971) and is superficially similar to the $2 n=38$ ("Oceanic") form of Rattus rattus. As indicated in plate 1 the $B$ chromosomes are small metacentrics, similar to those found in both the $2 n=38$ and $2 n=42$ forms of Rattus rattus.

Mitotic chromosome spreads were examined from leukocyte culture, bone marrow, corneal epithelium and from fibroblast culture from various sources (lung, heart, kidney, spleen, testis, ovary and body-wall). In rats where karyotypes were examined for more than one tissue, the number of $B$ chromosomes was constant within an individual (total numbers of $B$ chromosome-bearing rats examined for three or more tissues were: seven males, five females). Direct preparations from the livers of newborn rats also showed numbers of $B$ chromosomes identical to those from fibroblast cultures derived from the same individuals ( 3 males; 5 females). Anaphase/telophase spreads from corneal epithelium showed no evidence of unusual segregation of the $B$ chromosomes, that is, there was no obvious lagging of the $B s$.

Thus the $B s$ can be said to be "stable" in somatic tissues, unlike those in some other mammals, e.g., Echymipera kalabu, a marsupial bandicoot (Hayman et al., 1969).

The $G$ banded karyotype of $R$ attus fuscipes has been described by Yosida and Sagai (1973) and shown to differ from the $2 n=42$ form of Rattus rattus by two Robertsonian interactions. It is notable that these interactions are different from those relating the $2 n=38$ form of $R$ attus rattus to the $2 n=42$ form. As can be seen in plate 2(a) the $B$ chromosome is distinct from all the $A$ chromosomes in that it lacks strong bands, but shows a minor band at the distal end of the shorter arm.

The $C$ banded karyotype (plate $2(b)$ ) is characterised by very small centromeric bands on all the autosomes and the $X$ chromosomes, with the $Y$ chromosome and the $B$ chromosomes being almost completely $C$ positive. In the literature the term " $C$ positive" chromatin is generally used as a synonym for constitutive heterochromatin, which is in turn accepted as consisting largely of multiple copies of simple sequence DNA, with few genes coding for proteins (Pardue and Gall, 1970; Peacock et al., 1977). Although this implies that the $B$ chromosomes may contain DNA of different sequence arrangement to the standard (" $A$ ") chromosome complement, there is no biochemical evidence that the range of repeated sequence DNA in $B$ chromosomes is different to that found in the $A s$.

Detailed studies have now been done on the DNA of individual $R$. $f$. assimilis males with and without $B$ chromosomes, and no clear differences have been detected. Only a small proportion of the genome is made up of highly repeated sequences, which is consistent with the very small $C$ bands seen at metaphase. Whilst there is a consistent skewness towards the heavy $(G+C$ rich) side of the buoyant density profile in neutral Cesium Chloride gradients $\left(\mathrm{rho}=1.699 \mathrm{~g} / \mathrm{cm}^{3}\right.$ ), no cryptic satellite sequences have been resolved following use of $\mathrm{Ag}+, \mathrm{Hg}++$, Actinomycin-Dl or Hoechst 33258. Restriction endonuclease patterns for DNA from males with or without $B$ chromosomes were identical and indistiguishable from those published by 
Miklos et al., (1980). It would thus appear that the $B$ chromosomes of $R$. fuscipes assimilis do not contain any DNA sequences substantially different from those present in the standard chromosome complement. This is consistent with studies on $B$ chromosomes in other species (e.g., rye; Rimpau and Flavelt, 1976 and the grasshopper Myrmeleotettix maculatus; Dover and Henderson, 1976), and indicates that the $B s$ have not arisen from uncontrolled multiplication of a few simple sequence DNAs attached to a centric fragment. However, there is no evidence to show whether the $B s$ arose from a single $A$ chromosome or from segments of various $A$ chromosomes translocated onto a centric fragment.

Silver staining of the $R$. $f$. assimilis metaphase chromosomes showed that there are no active Nucleolus Organiser Regions present on the $B$ chromosomes (plate 3 ). This is not unexpected, since $B$ chromosomes have only rarely been reported to be associated with nucleoli.

\section{(ii) The meiotic chromosomes}

Meiosis was examined in twenty-seven male $R$. $f$. assimilis. The Acomplement behaves as expected, with the formation of 19 bivalents during the first meiotic prophase. The $B$ chromosomes, like the XY pair, are positively heteropycnotic in prophase I but slightly negatively pycnotic in metaphase I (plate. 4(a)). In individuals with the two $B$ chromosomes $(2 B s)$, the $B s$ appear to be paired at leptotene and zygotene (plate $4(\mathrm{~b})$ ) but are seen as univalents at diplotene/diakinesis (plate $4(\mathrm{c})$ ). In the single $3 B$ individual examined, there were usually three dark staining bodies at leptotene and zygotene, presumably the $X Y$ pair, a $B$ chromosome pair and a $B$ univalent. In all metaphase spreads, the $B s$ were seen as univalents.

These observations suggest that although the $B$ chromosomes may pair, there is almost certainly no chiasma formation between $B s$. Similar observations were made by Yong and Dahliwal (1972) and Pretel and Diaz de la Guardia (1978) for the $B$ chromosomes of Rattus rattus. Thus, for both species non-disjunction of $B$ chromosomes is likely to occur at the first division of male meiosis. Unfortunately, metaphase II spreads could not be scored accurately so all observations are limited to the first division. It is interesting to note that the $B s$ do not seem to associate with any $A$ chromosome pair, particularly in the light of observations by Solari and Ashley (1977) and de Boer and Branje (1979) that in some mammals (namely Psammomys obesus and Mus musculus) unpaired chromosomes, particularly the extra chromosomes in trisomics are usually seen in close association with the XY-pair at prophase I.

\section{(iii) $B$ Chromosome effects on chiasma frequency}

One of the most intriguing effects of $B$ chromosomes in many organisms is an apparent change in the chiasma frequency in $B$ chromosome individuals (Jones, 1975). The results presented in table 1 show that there is also a significant effect on chiasma frequency related to the presence of $B$ chromosomes in $R$. f. assimilis.

The Analysis of Variance (table 2) shows that there is fairly wide variation of chiasma frequency between animals. Despite this, there is a highly significant difference between the three chromosome groups $(0 B$, 


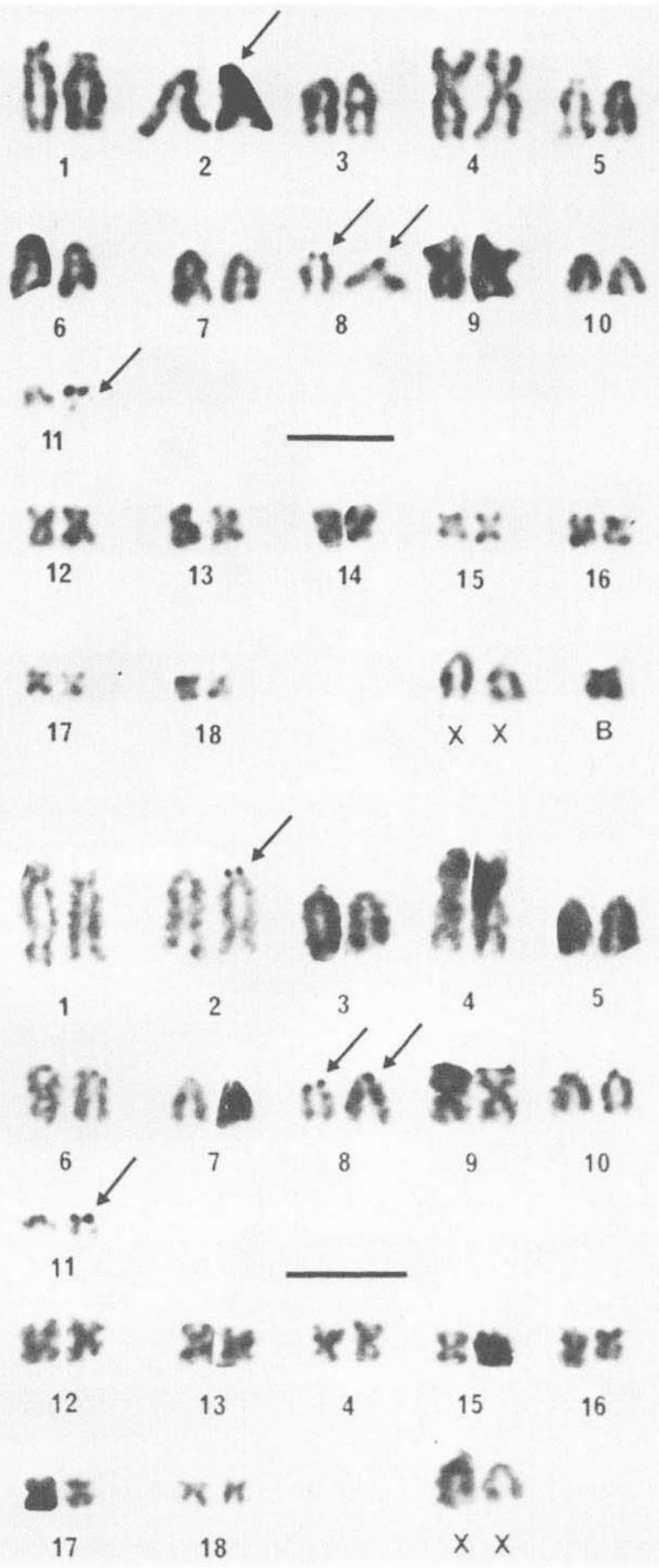

Plate 3. Nuclear Organiser Region banding. 
a

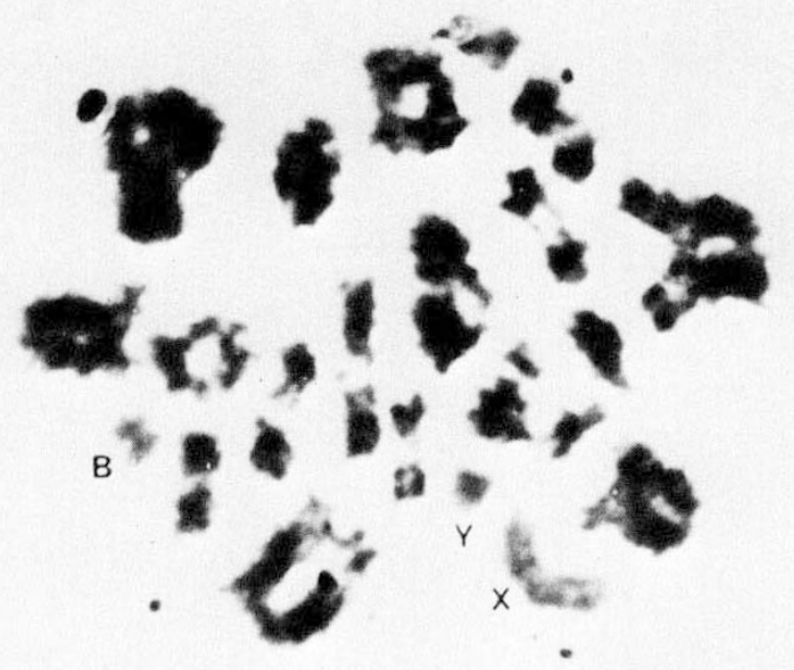

b

c
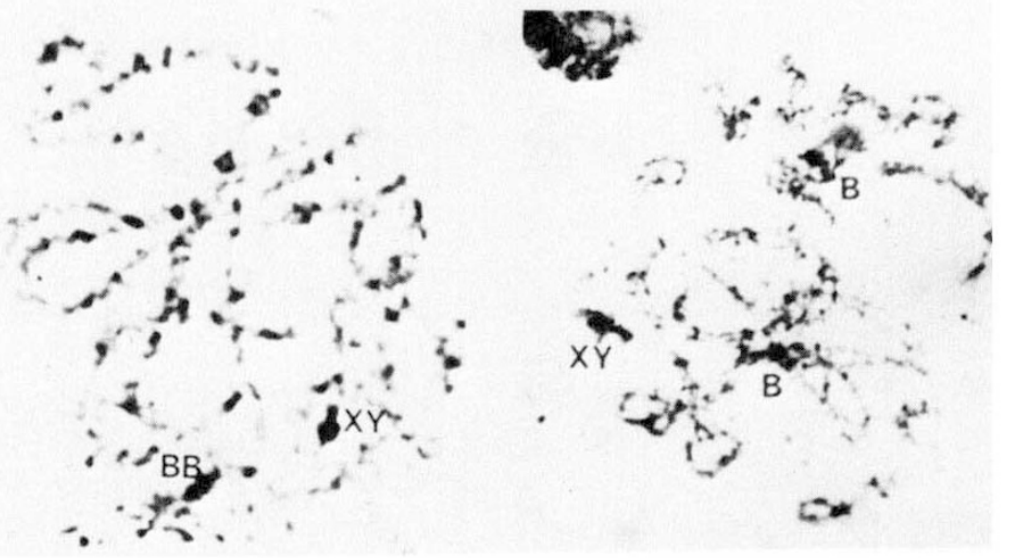

Plate 4. Male meiosis. (a) Metaphase $I$ in a $1 B$ individual. $B$ indicates the $B$ univalent. The $\mathrm{XY}$ pair has separated, as indicated. (b) Zygotene in a $2 B$ male. $B B$ indicates the heavily staining $B$ chromosome pair. $X Y$ indicates the sex chromosome pair. (c) Diplotene in a $2 B$ male. The $B$ chromosomes (labelled $B$ ) are not paired. 
TABLE 1

Mean number of chiasmata per cell within individuals, averaged over a number of individuals in three groups; those with no $B$ chromosomes $(O B)$, those with one $B$ chromosome $(1 B)$ and those with more than one $B$ chromosome $(2 B+3 B)$

\begin{tabular}{lccc}
\hline \multicolumn{1}{c}{$B$ Chromosome } & OB & $1 \mathrm{~B}$ & $2 \mathrm{~B}+3 \mathrm{~B}$ \\
Groups (N) & $(12)$ & $(9)$ & $(5+1)$ \\
\hline Mean cell chiasma & 28.38 & 29.75 & $\begin{array}{l}29.80 \\
\pm 1.24\end{array}$ \\
frequency \pm S.D. & \pm 0.59 & \pm 0.79 & \pm 1.9 \\
\hline
\end{tabular}

TABLE 2

Analysis of variance of chiasma frequency data

\begin{tabular}{lccc}
\hline \multicolumn{1}{c}{$\begin{array}{c}\text { Source of } \\
\text { variation }\end{array}$} & $\begin{array}{c}\text { Degrees of } \\
\text { freedom }\end{array}$ & $\begin{array}{c}\text { Mean } \\
\text { square }\end{array}$ & $\begin{array}{c}\text { Variance } \\
\text { ratio }\end{array}$ \\
\hline $\begin{array}{l}\text { Between chromosome } \\
\text { groups }\end{array}$ & 2 & $66 \cdot 05$ & $8 \cdot 641^{* * * \dagger}$ \\
$\begin{array}{l}\text { Between individuals } \\
\text { within group }\end{array}$ & 24 & 6.97 & $5 \cdot 174^{* * *}$ \\
Within individuals & 158 & $1 \cdot 35$ & \\
\hline
\end{tabular}

*** Significant at the $0 \cdot 1$ per cent level.

$\dagger$ Variance ratio for between chromosome groups/between individuals within groups is corrected for unequal sample sizes (Sokal and Rohlf, 1969).

$1 B$ and $2 B+3 B$ ). Student's $t$-tests show that the difference between the $1 B$ and $2 B+3 B$ groups is not significant, $(t=0.077, \mathrm{df}=13, p>0.05)$, but that the difference between $0 B$ and $1 B$ groups is highly significant $(t=4 \cdot 387$, $\mathrm{df}=19, p<0 \cdot 01$ ).

Thus, in Rattus fuscipes assimilis males, the presence of $B$ chromosomes is associated with an increase of mean cell chiasma frequency. This effect is not additive: $2 B$ and $3 B$ individuals have apparently similar mean chiasma frequencies to $1 B$ individuals. A similar "plateau" effect is seen in other $B$ chromosome-bearing species, e.g. Myrmeleotettix maculatus (John and Hewitt, 1965), Phaulacridium spp. (Westerman, 1977) and Perognathus baileyi (Patton, 1977).

Female meiosis was not studied because of the difficulties of obtaining oocytes from each individual. It cannot be assumed that chiasma frequencies would be the same in females as in males, nor that any effect would be in the same direction. Speed (1977) has shown that in the mouse, chiasma frequencies are different in males and females, and that ageing effects (chiasma frequencies tend to decrease with age in females) are different in males and females. Hewitt (1976) has shown that, in Myrmeleotettix maculatus, $B$ chromosomes do have different effects on chiasma frequencies in males and females. Whilst this point should be kept in mind, it would seem unlikely that the $B$ chromosome effects on mean cell chiasma frequency in females would negate those in males.

The mechanism by which the chiasma frequency is increased in the presence of $B$ chromosomes is unknown. Although a genic mechanism is 
of ten inferred, it should also be considered that a purely mechanical mechanism is possible as suggested by Rhoades and Dempsey (1972). One hypothesis can be made by extrapolating from the fact that $B$ chromosomes (unlike extra $A$ chromosomes-Verma and Lin, 1979) are correlated with an increase in the mitotic cell cycle time in some species (Jones 1975). If meiotic prophase $I$ is also lengthened in the presence of $B$ chromosomes, this may permit additional chiasmata to be formed. However, experiments by Fox et al., (1974) suggest that the meiotic cell cycle time is not lengthened by $\boldsymbol{B}$ chromosomes in Myrmeleotettix maculatus. Unfortunately, no other studies have been published which throw further light on this problem, and so the mechanism by which $B$ chromosomes affect $A$ chromosome chiasma frequency remains unclear.

What effect an increased chiasma frequency in male $R$. fuscipes may have at the population level is difficult to assess. If the extra chiasmata are not located telomerically, it can be assumed that $B$ carrying individuals would produce more recombinants, on average, than $0 B$ individuals, and thus would produce more phenotypic variability in their offspring. Moss (1966) showed that the offspring of $B$ carrying plants in experimental populations of rye did, indeed, show greater variability than the offspring of $0 B$ plants. However, because crossing was uncontrolled (i.e., the $B$ chromosome constitutions of the male parents were unknown) and because most of the factors measured (seed weight, number of grains per ear, growth rate etc.) are inter-correlated and influenced by maternal effects, the conclusions which can be drawn from this data are unclear.

Even if a change in the variability of offspring can be demonstrated, problems arise when interpreting the significance of such a change in the context of the natural population. Rees and Dale (1974), in their analysis of interpopulation chiasma frequency differences in some Lolium and Festuca species, suggested that an increase in the mean chiasma frequency of the population leads to a breakdown of adapted gene complexes with a concomitant release of variabilty in the population, but that much of the variability is then lost through selection acting against extreme recombinants. This process, they suggest, ultimately produces a specialised population with low variability and a high level of homozygosity in spite of high recombination frequency. However, it is implied that the increased recombination rate is maintained in the face of low comparative fitness by interpopulation or inter-deme selection. The necessary conditions for such selection to be effective are highly restrictive (small deme sizes, high rates of deme extinction and very low gene flow between demes; Levin and Kilmer 1973), and for this reason it seems unlikely that the model proposed by Rees and Dale (1974) is widely applicable. In general, any model for situations where there is advantage for individuals possessing high rates of recombination requires complex, varying environments. The theoretical manipulations become somewhat involved, and the role which $B$ chromosomes may play is difficult to determine. This is particularly so because of the general deleterious effect that $B$ chromosomes have on their hosts in many species, including Rattus fuscipes (Thomson, 1984).

Acknowledgments. Part of this work was done whilst one of us (R.T.) was in receipt of a LaTrobe University Postgraduate Research Scholarship. The capture, holding and occasional sacrifice of $R$. fuscipes was carried out under permits issued by the Fisheries and Wildlife 
Division of the Ministry for Conservation (Victoria). We would like to thank Dr Chris Collet, who either performed or assisted with most of the DNA analysis.

\section{REFERENCES}

BAtTAglia, E. 1964. Cytogenetics of $B$ chromosomes. Caryologia, 17, 246-299.

BAVERSTOCK, P. R., WATTS, C. H. S., HOGARTH, J. T., ROBINSON, A. C. AND ROBINSON, J. F. 1977. Chromosome evolution in Australian rodents II. The Rattus group. Chromosoma, $61,227-241$.

DE BOER, P. AND BRANJE, H. E. B. 1979. Association of the extra chromosome in tertiary trisomic mice with the sex chromosome during first meiotic prophase, and its significance for impairment of spermatogenesis. Chromosoma, 73, 369-379.

DE BOER, P., VAN BUUL, P., VAN BEEK, R., VAN DER HORVEN, F. AND NATARAJAN, A. 1977. Chromosomal radiosensitivity and karyotype in mice using cultured peripheral blood, and comparison with this system in man. Mutation Res., 42, 379-394.

DOVER, G. A. AND HENDERSON, S. A. 1976. No detectable satellite DNA in supernumerary chromosomes of the grasshopper Myrmeleottix. Nature, 259, 57-59.

EVANS, E. P., BURTENSHAW, M. D. AND FORD, C. E. 1972. Chromosomes of mouse embryos and newborn young: preparations from membranes and tail tips. Stain. Techn., 47, 229-234.

FREDGA, K. 1964. A simple technique for the demonstration of chromosomes and mitotic stages in a mammal: chromosomes from the cornea. Hereditas, 51, 268-273.

FOX, D. P., HEWITT, G. M. AND HALL, D. J. 1974. (1972) DNA translation and RNA transcription of euchromatic and chromosome regions during grasshopper meiosis. Chromosoma, 45, 43-62.

GILEVA, E. A. AND CHEBOtAR, N. A. 1979. Preovulatory stages of gametogenesis, the sex chromosome and $B$ chromosome behaviour at female meiosis of Dicrostonyx torquatus Pall. Tsitologiya, 21, 798-801.

HAYMAN, D. C., MARTIN, P. G. AND WALLER, P. F. 1969. Parallel mosaicism of supernumerary chromosomes and sex chromosomes in Echymiperakalabu (Marsupialia). Chromosoma, $27,371-80$

HEWITT, G. M. 1976. Meiotic drive for $B$ chromosomes in the primary oocytes of Myrmeleotettix maculatus (Orthoptera; Acrididae). Chromosoma, 56, 381-391.

JOHN, B. AND HEWITT, G. M. 1965. The $B$ chromosome system of Myrmeleotettix maculatus (Thunb.). II. The statics. Chromosoma (Berl.), 17, 121-135.

JONES, R. N. 1975. B chromosome systems in flowing plants and animal species. Int. Rev. Cytol., 40, 1-99.

JOVANOVIC, V. AND ATKINS, L. 1969. A tissue culture technique for study of avian chromosomes. The Auk, 86, 696-700.

LEVIN, B. R. AND KILMER, W. L. 1973. Interdemic selection and the evolution of altruism: A computer simulation. Evolution, 28, 527-595.

MIKLOS, G. L. G., WILLCOCKS, D. A. AND BAVERSTOCK, P. R. 1980. Restriction endonuclease and molecular analyses of three rat genomes with special reference to chromosome rearrangement and speciation problems. Chromosoma, 76, 339-363.

MOSS, J. P. 1966. The adaptive significance of $B$ chromosomes in Rye. Chromosomes Today, $1,15-25$.

MUNKE, M. AND SCHMAIADY, H. 1979. A simple one-step procedure for staining nucleolus organiser regions. Experientia, 35, 602-603.

MUNTZiNG, A. 1974. Accessory chromosomes. Ann. Rev. Genet., 8, 243-266.

PARDUE, M. L. AND GALL, J. G. 1970. Chromosomal localisation of mouse satellite DNA. Science, 168, 1356-1358.

PATTON, J. L. 1977. B chromosome systems in the pocket-mouse, Perognathus baileyi: Meiosis and $C$ band studies. Chomosoma, 60,1-14.

PEACOCK, W. J., LOHE, A. R., GERLACK, W. L., DUNSMUIR, P., DENNIS, E. S. AND APPELS, R. 1977. Fine structure and evolution of DNA in heterochromatin. Cold Spring Harbour Symp. Quant. Biol., 38, 1121-1135.

PRETEL, M. A. AND DIAZ DE LA GUARDIA, G. R. 1978. Chromosomal polymorphism caused by supernumerary chromosomes in Rattus rattus spp. frugivurus (sic.) (Raffinesque, 1814) (Rodentia, Muridae). Experientia, 34, 325-328.

REES, H. AND DALE, D. J. 1974. Chiasmata and variability in Lolium and Festuca populations. Chromosoma, 47, 335-351. 
RHOADES, M. M. AND DEMPSEY, E. 1972. On the mechanism of chromatin loss induced by the $B$ chromosomes of maize. Genetics, 71, 73-96.

RIMPAU, J. AND FLAVELL, R. B. 1976. The repeated sequence DNA of $B$ chromosomes in Rye. Proc. Nat. Acad. Sci. U.S.A., 57, 1626-1632.

SHELLHAMMER, H. S. 1969. Supernumerary chromosomes of the harvest-mouse Reithrodontomys megalotis. Chromosoma, 27, 102-108.

SOKAL, R. R. AND ROHLF, F. J. 1969. Biometry: The Principles and Practice of Statistics in Biological Research. W. H. Freeman and Co., San Francisco.

SOLARI, A. J. AND ASHLEY, T. 1977. Ultrastructure and behaviour of the achiasmatic, telosynaptic XY pair of the sand-rat (Psammomys obesus). Chromosoma, 62, 319-336.

SPEED, R. M. 1977. The effects of ageing on the meiotic chromosomes of male and female mice. Chromosoma, 64, 241-254.

STOCK, A. D., BURNHAM, D. B. AND HSU, T. C. 1972. Giemsa banding of meiotic chromosomes with a description of a procedure for cytological preparations from solid tissues. Cytogenetics, 11, 534-539.

THOMSON, R. L. 1984. B chromosomes in Rattus fuscipes assimilis. II. The transmission of $B$ chromosomes to offspring and population studies: support for the "parasitic" model. Heredity, 52, 363-372.

VERMA, R. S. AND LIN, M. S. 1979. The duration of DNA synthetic (S) period of Zea mays: a genetic control. Theor. Appl. Genet., 54, 277-282.

volobujEV, V. T. 1981. B chromosomes system of the mammals. Caryologia, 34, 1-24.

Westerman, M. 1977. Population cytology of the genus Phaulacridium. Heredity, 34, 11-27.

YONG, H. S. AND DHALIWAL, S. S. 1972. Supernumerary $(B)$ chromosomes in the Malayan house rat Rattus rattus diardii (Rodentia, Muridae). Chromosoma, 36, 256-262.

YOSIDA, T. H. 1977. Supernumerary chromosomes in the black rat (Rattus rattus) and their distribution in three geographic variants. Cytogenet. Cell Genet., 18, 149-159.

YOSIDA, T. H., TSUCHIYA, K. AND MORIWAKI, K. 1971. Karyotype differences of black rats (Rattus rattus), collected in various localities of East and Southeast Asia and Oceania. Chromosoma, 32, 252-267.

YOSIDA, T. H. AND SAGAI, T. 1973. Similarity of giemsa banding patterns of chromosomes in several species of the genus Rattus. Chromosoma, 41, 3-101. 